Wright State University

CORE Scholar

$12-1-2002$

\title{
Si Doping of High-Al-Mole Fraction AlxGa1-xN Alloys with rf Plasma-Induced Molecular-Beam-Epitaxy
}

Jeonghyun Hwang

William J. Schaff

Lester F. Eastman

Shawn T. Bradley

Leonard J. Brillson

See next page for additional authors

Follow this and additional works at: https://corescholar.libraries.wright.edu/physics

Part of the Physics Commons

\section{Repository Citation}

Hwang, J., Schaff, W. J., Eastman, L. F., Bradley, S. T., Brillson, L. J., Look, D. C., Wu, J., Walukiewicz, W., Furis, M., \& Cartwright, A. N. (2002). Si Doping of High-Al-Mole Fraction AlxGa1-xN Alloys with rf PlasmaInduced Molecular-Beam-Epitaxy. Applied Physics Letters, 81 (27), 5192-5194.

https://corescholar.libraries.wright.edu/physics/80

This Article is brought to you for free and open access by the Physics at CORE Scholar. It has been accepted for inclusion in Physics Faculty Publications by an authorized administrator of CORE Scholar. For more information, please contact library-corescholar@wright.edu. 


\section{Authors}

Jeonghyun Hwang, William J. Schaff, Lester F. Eastman, Shawn T. Bradley, Leonard J. Brillson, David C. Look, J. Wu, Wladek Walukiewicz, Madalina Furis, and Alexander N. Cartwright 


\title{
Si doping of high-Al-mole fraction $\mathrm{Al}_{x} \mathrm{Ga}_{1-x} \mathrm{~N}$ alloys with rf plasma-induced molecular-beam-epitaxy
}

\author{
Jeonghyun Hwang, ${ }^{\text {a) }}$ William J. Schaff, and Lester F. Eastman \\ Department of Electrical and Computer Engineering, Cornell University, Ithaca, New York 14853
}

Shawn T. Bradley and Leonard J. Brillson

Department of Electrical Engineering, The Ohio State University, Columbus, Ohio 43210

David C. Look

Semiconductor Research Center, Wright State University, Dayton, Ohio 45435

J. Wu and Wladek Walukiewicz

Materials Sciences Division, Lawrence Berkeley National Laboratory, Berkeley, California 94720

Madalina Furis and Alexander N. Cartwright

Department of Electrical Engineering, State University of New York at Buffalo, Buffalo, New York 14260

(Received 12 September 2002; accepted 8 November 2002)

\begin{abstract}
Very high levels of $n$-type doping of $\mathrm{Al}_{x} \mathrm{Ga}_{1-x} \mathrm{~N}$ alloys were recently achieved by rf plasma-induced molecular-beam epitaxy on sapphire substrates and $\mathrm{Si}$ as a dopant. Electron concentrations were obtained up to $1.25 \times 10^{20} \mathrm{~cm}^{-3}$ when the Al mole fraction was $50 \%$, and $8.5 \times 10^{19} \mathrm{~cm}^{-3}$ electrons were measured even when the $\mathrm{Al}$ mole fraction was $80 \%$. Other material properties were determined by optical absorption, photoluminescence, cathodoluminescence, $\mathrm{x}$-ray diffraction, and atomic force microscopy measurements and high optical and morphological qualities were shown. (c) 2002 American Institute of Physics. [DOI: 10.1063/1.1534395]
\end{abstract}

Successful doping of AlGaN is essential for the realization of many device applications, but it has been known that $\mathrm{AlGaN}$ suffers a rapid decrease in the conductivity with increasing $\mathrm{Al}$ mole fraction. ${ }^{1}$ The unintentional $n$-type conductivity in $\mathrm{AlGaN}$ has been attributed to the incorporation of nitrogen vacancies or oxygen impurities during growth. ${ }^{2}$ In the case of $n$-type doping with oxygen, there were reports that shallow oxygen donor is converted to a deep level by a $D X$ transition when $x>0.4$ causing a decrease in the $n$-type conductivity. ${ }^{3-5}$ For intentional $n$-type doping of AlGaN, Si is the most widely used dopant. However, the Si donor depth increases with increasing $\mathrm{Al}$ mole fraction. There are also reports on the $D X$ state or a localized deep state formation of $\mathrm{Si}$ in AlN. It was reported that $\mathrm{Si}$ could have a stable deep $D X$ state in AlN and doping efficiency decreases with increasing $\mathrm{Al}$ content, ${ }^{3,6}$ while other researchers proposed that $\mathrm{Si}$ remains a shallow donor over the whole range of $\mathrm{Al}_{x} \mathrm{Ga}_{1-x} \mathrm{~N} .{ }^{4}$ Experimentally, there have been few reports on high $n$-type conductivity in high $\mathrm{Al}$ mole fraction AlGaN. Si doped $\mathrm{Al}_{x} \mathrm{Ga}_{1-x} \mathrm{~N}$ grown by molecular-beam epitaxy (MBE) on a $\mathrm{Si}$ wafer was reported to have $8 \times 10^{19} \mathrm{~cm}^{-3}$ electron density when $x=0.4,{ }^{7}$ and $\mathrm{Al}_{x} \mathrm{Ga}_{1-x} \mathrm{~N}$ :Si grown by metalorganic vapor-phase epitaxy was reported to exhibit 3.1 $\times 10^{18} \mathrm{~cm}^{-3}$ electron concentrations when $x=0.58 .^{8}$ In this letter, doping and materials properties of heavily Si-doped, high $\mathrm{Al}$ mole fraction $\mathrm{AlGaN}$ were investigated.

$\mathrm{Si}$-doped $\mathrm{AlGaN}$ was grown in a turbomolecular pumped Varian Gen II MBE system which uses standard effusion cells for the group III elements. An EPI RF plasma source was used for the nitrogen source and 2 in. sapphire wafers

${ }^{a)}$ Electronic mail: jh124@cornell.edu with $c$-plane orientation were used as substrates. After loading into the growth chamber, each wafer was nitrided by nitrogen plasma at $200{ }^{\circ} \mathrm{C}$ for $30 \mathrm{~min}$ and then heated to $830^{\circ} \mathrm{C}$ for AlN nucleation layer growth. Si-doped AlGaN wafers with different $\mathrm{Al}$ mole fractions and $\mathrm{Si}$ fluxes were grown at $800^{\circ} \mathrm{C}$, after the deposition of $200 \AA$ AlN. The growth rate of each sample was almost the same, about 4000 $\AA / \mathrm{h}$. The $\mathrm{Al}$ mole fraction was determined by $\mathrm{x}$-ray diffraction measurements. The thickness of each of the AlGaN samples was about $4000 \AA$ and all of them were assumed to be completely relaxed.

Figure 1 shows the dependence of electron density, $n$, on Al mole fraction, $x$, when the $\mathrm{Si}$ furnace temperature was $1300^{\circ} \mathrm{C}$. With a fixed Si flux, capacitance-voltage $(C-V)$ measurements show that electron density falls from 1 $\times 10^{19} \mathrm{~cm}^{-3}$ to $5 \times 10^{18} \mathrm{~cm}^{-3}$ with increasing Al mole frac-

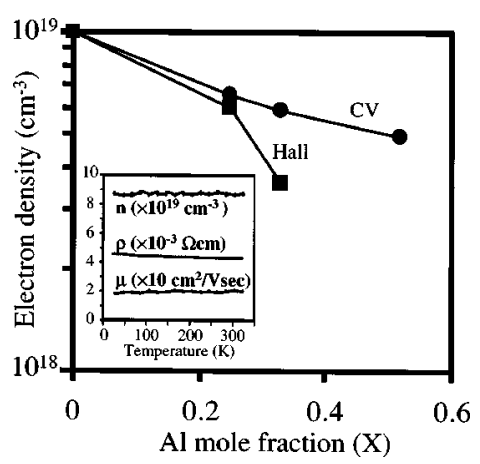

FIG. 1. The dependence of electron density on Al mole fraction, obtained by $C-V$ and Hall measurements, when $\mathrm{Si}$ furnace temperature was fixed at $1300{ }^{\circ} \mathrm{C}$. The inset is the variable temperature Hall measurement result of $65 \% \mathrm{Al}$ mole fraction AlGaN:Si with a increasing Si flux. Electron density, resistivity, and electron mobility do not change with varying temperature. 


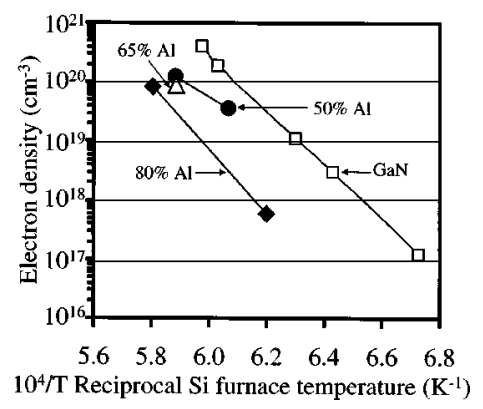

FIG. 2. Electron density in the $\mathrm{Al}_{x} \mathrm{Ga}_{1-x} \mathrm{~N}$ as a function of reciprocal $\mathrm{Si}$ furnace temperature.

tion from $x=0$ to $x=0.5$, which is expected if the donor levels are becoming deeper with increasing Al content. Note in Fig. 1 that $n_{C-V}>n_{\text {Hall }}$ for the higher $x$ values, because deeper donors can contribute to capacitance even though they are not contributing free electrons. Note that all the following electron density and mobility data in this letter were measured by the Hall method and actual Si concentrations of all samples are now under investigation. Figure 2 shows the electron density of different Al mole fraction $\mathrm{Al}_{x} \mathrm{Ga}_{1-x} \mathrm{~N}$ samples as a function of reciprocal $\mathrm{Si}$ furnace temperature. With increasing Si fluxes, higher electron densities, up to $1.25 \times 10^{20} \mathrm{~cm}^{-3}$, were obtained when $x=0.5$. $8.5 \times 10^{19} \mathrm{~cm}^{-3}$ electron concentration was also achieved when the Al mole fraction was up to $80 \%$. The threshold temperature of the $\mathrm{Si}$ furnace for conducting AlGaN increased as the Al mole fraction increased. The minimum electron density that could be measured by the Hall method also increased with increasing $\mathrm{Al}$ mole fraction, except one data point in $80 \% \mathrm{Al}$ mole fraction. Variable temperature Hall measurements were performed in order to find the $\mathrm{Si}$ donor ionization energy, but there was no variation at all in the electron density with varying temperature, indicating that the samples were highly degenerate. The results for $65 \% \mathrm{Al}$ mole fraction $\mathrm{AlGaN}$ with $8.8 \times 10^{19} \mathrm{~cm}^{-3}$ electron density and $18 \mathrm{~cm}^{2} / \mathrm{V} \mathrm{s}$ Hall mobility are shown in the inset of Fig. 1.

At very high Si doping density, the Bohr orbital of donor probably overlaps each other. From the Mott-transition condition, $N_{D}$ (Mott) $\cong\left(0.24 / a_{B}\right)^{3}, N_{D}$ (Mott) is estimated to be $8 \times 10^{18} \mathrm{~cm}^{-3}$ for the $65 \% \mathrm{Al}$ mole fraction AlGaN, where $a_{B}$ is the Bohr radius of donor electron. Anything above this has metallic, temperature independent conductivity. As the result of the interactions of donors, donor band would start to form near the $N_{D}$ (Mott) or at a little lower concentration than the $N_{D}$ (Mott), and at even higher doping density the donor band would widen and finally merge with the conduction band. The increase of the minimum measurable electron density, $n_{\text {min }}$, with increasing Al mole fraction, $x$, suggests that an unknown acceptor is also increasing with $x$ and that this acceptor has a concentration $N_{A}$ of roughly $n_{\min }$. It is possible that previous attempts to dope AlGaN at high $x$ values failed because the unknown acceptor concentration was too high. In this regard, the very low oxygen contamination of this MBE machine can be another important factor. Secondary ion mass spectroscopy measurements of our MBE grown GaN did not show any oxygen signal within the detection limit (mid $10^{16} \mathrm{~cm}^{-3}$ ) and the GaN was always insulating if there was no intentional doping. This low oxygen

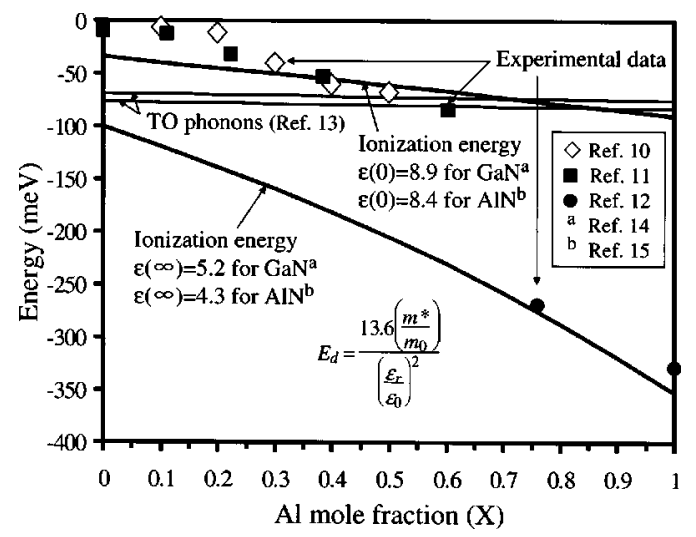

FIG. 3. Theoretical and experimental Si donor ionization energies in AlGaN as a function of $\mathrm{Al}$ mole fraction, with $\mathrm{TO}$ phonon energies of $\mathrm{AlGaN}$.

contamination can reduce problems associated with $\mathrm{Al}$ and enable us to grow higher quality materials.

However, these techniques have not been successful in growing conducting $\mathrm{Al}_{x} \mathrm{Ga}_{1-x} \mathrm{~N}$ when $x>0.8$. It is interesting that this result coincides well with a theory of dielectric constant change. ${ }^{9}$ Figure 3 shows the theoretical Si donor ionization energies in $\mathrm{AlGaN}$ with reported experimental data. $^{10-12}$ TO phonon energies of AlGaN are also shown. ${ }^{13}$ From a simple hydrogen model, donor ionization energy of $\mathrm{Al}_{x} \mathrm{Ga}_{1-x} \mathrm{~N}$ increases from $34 \mathrm{meV}(x=0)$ to $90 \mathrm{meV}(x$ $=1$ ) when low-frequency dielectric constants are used. The electron effective mass used here was $0.2 m_{0}(1-x)$ $+0.48 m_{0} x$ for $\mathrm{Al}_{x} \mathrm{Ga}_{1-x} \mathrm{~N}$, applying Vegard's law. ${ }^{14,15}$ According to the theory, it is necessary to use high-frequency dielectric constant, $\epsilon(\infty)$, rather than the low-frequency value, $\epsilon(0)$, when the ionization energy is larger than the transverse optical phonon energy. In AlGaN, this occurs when the $\mathrm{Al}$ mole fraction is larger than $\sim 80 \%$. Due to the smaller value of $\epsilon(\infty)$, the donor ionization energy would become much deeper abruptly, when $x>\sim 0.8$. This agrees well with the experimental data. The radius of Si donor electron's wave function also becomes much smaller in that case and a higher doping density would be needed for degeneracy. This may explain why degenerate doping was difficult to achieve for $x>0.8$. Recently, there was a report on conducting Si-doped AlN. ${ }^{16}$ The ionization energy data in that report also show a sudden increase in the Si donor ionization energy near $80 \%$ Al mole fraction, even though the ionization energy is much smaller, $83 \mathrm{meV}$ in AlN, than $320 \mathrm{meV}$ in the Ref. 12.

A theoretical AlGaN band gap with experimental data of AlGaN:Si obtained by light absorption, photoluminescence (PL), and cathodoluminescence (CL) is shown in Fig. 4. The bowing parameter used for AlGaN band gap calculation was $1.3 \mathrm{eV} .^{17}$ The optical absorption data are in good agreement with the theoretical band gap expectation and the absorption spectra in the inset shows that band edge absorption with heavy Si doping does not have any added significant features. The Burstein-Moss shift observed in a heavily doped semiconductor is not noticeable in the AlGaN:Si and no deep levels or other absorption centers are introduced, which would absorb UV light. These features make the AlGaN:Si very promising materials for UV light emitters or detectors. It seems that band filling effect competes with band tailing and band gap renormalization. PL and CL data show the 


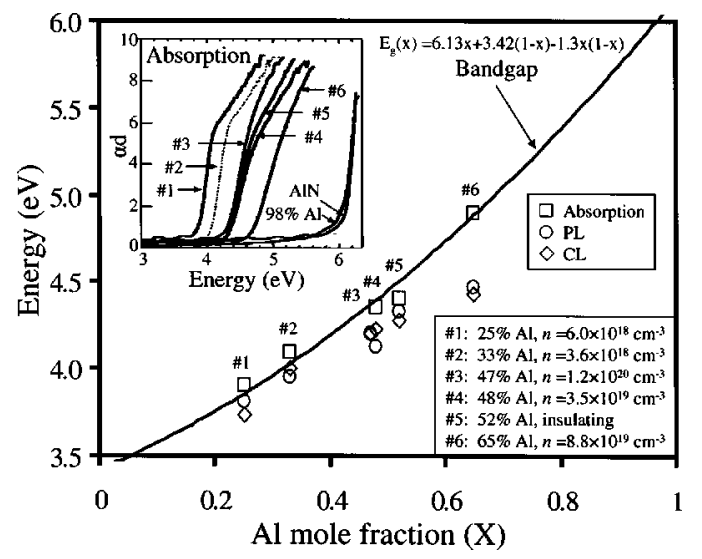

FIG. 4. Theoretical graph of AlGaN band gap as a function of Al mole fraction, with the experimental data of AlGaN:Si measured by optical absorption, PL, and CL. Each sample has different Al mole fraction and electron density, $n$. The inset shows the optical absorption spectra of the $\mathrm{AlGaN}$ :Si samples. Samples above $80 \% \mathrm{Al}$ are insulating.

same trend but have a little lower energy. This may be explained as PL and CL likely come from electrons in the bottom of the band, because they have better $k$ conservation with the holes, which are near $k=0$. Also, there could be the band tailing effect, and the localization effect resulting from compositional variation. The PL lifetime was around $180 \mathrm{ps}$ with insignificant dependence on $\mathrm{Al}$ mole fraction or doping density.

In contrast to $\mathrm{GaN}: \mathrm{Si}^{18}$ causing rough surface, the rms surface roughness measured by atomic force microscopy (AFM) was significantly smaller for AlGaN:Si layers. The rms value of $80 \%$ and $65 \% \mathrm{Al}$ mole fraction $\mathrm{AlGaN}$ samples with $\sim 1 \times 10^{20} \mathrm{~cm}^{-3}$ electron density was 1.2 and $1.3 \mathrm{~nm}$, respectively, and two-dimensional step growth was observed in these samples with concentric and spiral shape steps. There was no disadvantage of high Si doping on the AlGaN surface morphology and the morphology was even improved with Si doping. It was hard to find a general trend of morphology change as a function of electron density. Also, no consistent correlation was observed between the full width at half maximum (FWHM) of x-ray measurements of $\mathrm{AlGaN}: \mathrm{Si}$ and the electron density. In the $2 \theta$-scan mode, the smallest value of FWHM was $\sim 9$ arc min when the $\mathrm{Al}$ mole fraction was $0 \%$, or $100 \%$ and the FWHMs of other Si-doped AlGaN layers varied within $\sim 24$ arc min.
In conclusion, very high $n$-type doping, $\sim 10^{20} \mathrm{~cm}^{-3}$ electron density, of $\mathrm{Al}_{x} \mathrm{Ga}_{1-x} \mathrm{~N}$ layers was successfully achieved by MBE in the range of $0 \leqslant x \leqslant 0.8$. Despite the very high $\mathrm{Si}$ doping density, there was no significant degradation of materials properties, and, in fact, the layers showed superior optical and structural qualities suitable for device applications.

This research was supported by ONR (Contract Nos. N00014-99-10714 and N00014-00-1-0042), AFOSR (Grant No. F49620-00-1-0347), and NSF (Contract Nos. 0123453 and DMR-0076362).

${ }^{1}$ M. D. Bremser, W. G. Perry, T. Zheleva, N. V. Edwards, O. H. Nam, N. Parikh, D. E. Aspnes, and R. F. Davis, MRS Internet J. Nitride Semicond. Res. 1, 8 (1996).

${ }^{2}$ P. Perlin, T. Suski, M. Leszczynski, I. Grzegory, J. Jun, S. Porowski, P. Boguslawski, J. Bernholc, J. C. Chervin, A. Polian, and D. Moustakas, Phys. Rev. Lett. 75, 296 (1995)

${ }^{3}$ C. H. Park and D. J. Chadi, Phys. Rev. B 55, 12995 (1997).

${ }^{4}$ C. G. Van de Walle, Phys. Rev. B 57, R2033 (1998).

${ }^{5}$ C. Stampfl and C. G. Van de Walle, Appl. Phys. Lett. 72, 459 (1998).

${ }^{6}$ P. Boguslawski and J. Bernholc, Phys. Rev. B 56, 9496 (1997).

${ }^{7}$ M. A. Sánchez-García, E. Calleja, F. B. Naranjo, F. J. Sánchez, F. Calle, E. Muñoz, A. M. Sánchez, F. J. Pacheco, and S. I. Molina, J. Cryst. Growth 202, 415 (1999).

${ }^{8}$ M. D. Bremser, W. G. Perry, O. H. Nam, D. P. Griffis, R. Loesing, D. A. Ricks, and R. F. Davis, J. Electron. Mater. 27, 229 (1998).

${ }^{9}$ J. W. Orton, Semicond. Sci. Technol. 10, 101 (1995).

${ }^{10}$ M. Ahoujja, J. L. McFall, Y. K. Yeo, R. L. Hengehold, and J. E. Van Nostrand, Mater. Sci. Eng., B 91, 285 (2002).

${ }^{11}$ A. Y. Polyakov, N. B. Smirnov, A. V. Govorkov, M. G. Milvidskii, J. M. Redwing, M. Shin, M. Skowronski, D. W. Greve, and R. G. Wilson, SolidState Electron. 42, 627 (1998).

${ }^{12}$ M. Stutzmann, O. Ambacher, A. Cros, M. S. Brandt, H. Angerer, R. Dimitrov, N. Reinacher, T. Metzger, R. Höpler, D. Brunner, F. Freudenberg, R. Handschuh, and Ch. Deger, Mater. Sci. Eng., B 50, 212 (1997).

${ }^{13}$ M. Holz, T. Prokofyeva, M. Seon, K. Copeland, J. Vanbuskirk, S. Williams, S. A. Nikishin, V. Tretyakov, and H. Temkin, J. Appl. Phys. 89, 7977 (2001).

${ }^{14}$ S. N. Mohammad and H. Morkoc, Prog. Quantum Electron. 20, 361 (1996).

${ }^{15}$ V. W. L. Chin, T. L. Tansley, and T. Osotchan, J. Appl. Phys. 75, 7365 (1994).

${ }^{16}$ Y. Taniyasu, M. Kasu, and N. Kobayashi, Appl. Phys. Lett. 81, 1255 (2002).

${ }^{17}$ D. Brunner, H. Angerer, E. Bustarret, F. Freudenberg, R. Höpler, R. Dimitrov, O. Ambacher, and M. Stutzmann, J. Appl. Phys. 82, 5090 (1997).

${ }^{18} \mathrm{http}: / /$ www.iiiv.cornell.edu/www/schaff/muri/reports/fy97q2/2nd.html 